\title{
First Report of Botrytis Mold Caused by Botrytis cinerea on Peonies (Paeonia lactiflora Pall.)
}

*Corresponding author

Tel: +82-62-530-2071

Fax: $+82-62-530-0208$

E-mail:yckimyc@jnu.ac.kr

ORCID

https://orcid.org/0000-0002-7661-7600

\author{
Hyo Jeong Kim ${ }^{1}$, Min Young Park ${ }^{2}$, Kyung-Cheol $\mathrm{Ma}^{2}$, and Young Cheol Kim ${ }^{3 *}$ \\ ${ }^{\prime}$ Environment-Friendly Agriculture Research Institute, Jeollanamdo Agricultural Research \& Extension \\ Services, Naju 58213, Korea \\ ${ }^{2}$ Horticultural Research Institute, Jeollanamdo Agricultural Research \& Extension Services, Naju 58213, Korea \\ ${ }^{3}$ Department of Applied Biology, Chonnam National University, Gwangju 61186, Korea
}

Received September 12, 2020

Revised November 12, 2020

Accepted November 12, 2020

\begin{abstract}
In 2019, symptoms of Botrytis mold on the peony (Paeonia lactiflora Pall.) 'Sarah Bernhardt' were observed during a survey of the commercial greenhouses of Gangjin County, South Korea. The initial symptoms, small brown spots, were observed mainly at the leaf margins. The lesions extended to the interior of leaves forming irregular spots in which abundant conidia developed. Fungal colonies were obtained from surface-sterilized tissue excised from growing edges of the lesions that were transferred to potato dextrose agar. Melanized irregular sclerotia were formed in these colonies after 40 days at $8^{\circ} \mathrm{C}$. Molecular phylogeny based on sequences of genes for glyceraldehyde-3-phosphate dehydrogenase, heat-shock protein 60, and RNA polymerase subunit II were highest for the PBC-2 isolate to the type strains of Botrytis cinerea, rather than other Botrytis species associated with peony diseases. Following Koch's postulates, healthy Sarah Bernhardt plants were inoculated with a foliar application of conidial suspensions of the isolate PBC-2. Following incubation under humidity with a $12 \mathrm{hr}$ photoperiod for 7 days, symptoms developed on the leaf margins that were identical to those observed in the greenhouses. This study is the first report of Botrytis blight caused by B. cinerea on peonies grown in commercial greenhouses in South Korea.
\end{abstract}

Keywords: Botrytis mold, Paeonia lactiflora, Peony
Herbaceous peonies (Paeonia lactiflora Pall.) are grown for high-value cut flowers, as well as for medicinal purposes (Garfinkel and Chastagner, 2018). They are grown throughout the temperate regions of the world. In South Korea, peonies are mainly cultivated in Gangjin County $\left(34^{\circ} 48^{\prime} \mathrm{N}\right.$, $126^{\circ} 85^{\prime} \mathrm{E}$ ) of Jeonnam Province. In June 2019, symptoms of a leaf blight were observed on greenhouse-grown peony (Paeonia lactiflora Pall. 'Sarah Bernhardt') with a disease incidence of $50-60 \%$.

The initial symptoms of the disease in commercial greenhouses were small brown spots on the edges of leaves.

Research in Plant Disease

pISSN 1598-2262, elSSN 2233-9191

www.online-rpd.org
The diseased tissue then gradually spread to the interior of the leaf, forming irregularly-shaped necrotic lesions (Fig. 1A). Abundant conidia were formed within the lesions and flowers, being visible using a portable binocular. These symptoms were similar to those reported for peonies infected by Botrytis isolates (Garfinkel et al., 2017). Symptoms in herbaceous peonies were shown to arise from three different Botrytis species, which could be distinguished using molecular phylogeny (Garfinkel et al., 2017). These species were $B$. cinerea, $B$. paeoniae, and a novel species called $B$. euroamericana (Garfinkel et al., 2017). Speciation of Botrytis isolates has continued to diversify (Garfinkel and Chastagner, 2019). Indeed, in a study on 178 isolates with pathogenicity in peonies from the Pacific Northwest in the United States, $15 \%$ were not assigned by molecular phylogeny to known species (Garfinkel and Chastagner, 2019). In a comparison

(c) The Korean Society of Plant Pathology

(c) This is an open access article distributed under the terms of the Creative Commons Attribution Non-Commercial License (http://creativecommons.org/licenses/ by-nc/4.0/), which permits unrestricted non-commercial use, distribution, and reproduction in any medium, provided the original work is properly cited. 
of peony isolates from Washington and Oregon to those from Alaska, different patterns in the dominant species were observed with isolates identified as $B$. cinerea comprising $29 \%$ and $40 \%$, respectively (Garfinkel and Chastagner, 2019). Some Botrytis isolates are generally capable of causing disease on a variety of hosts, whereas others are host specific. For example, B. cinerea can cause disease on over 500 hosts, including peonies. Consequently, identification of the pathogen species could be important in determining potential risks to peonies and other crops.

To isolate the causal pathogen from the commercial greenhouses in Gangjin County, approximately 10 different lesions were excised, surface sterilized by immersion in $70 \%$ ethanol for $30 \mathrm{sec}$ and then in 1\% sodium hypochloride for $1 \mathrm{~min}$ before being rinsed three times with sterile distilled water. Each sample was placed on potato dextrose agar (PDA; Difco, Detroit, MI, USA) and incubated at $20 \pm 2^{\circ} \mathrm{C}$ for 7 days to allow sporulation under dark conditions. Five, purified fungal cultures were obtained, each from the growth of single spores on water agar (Choi et al., 1999), and one representative isolate, PBC-2, was chosen for additional studies. The morphological characteristics of colonies of PBC-2, when grown on PDA under dark conditions, was within the wide variability observed in Botrytis sp. (Ellis and Waller, 1974; Garfinkel and Chastagner, 2019). Variation in morphology is extreme in these species, as illustrated by the appearance of different colonies 30 undefined species in the characterization study of Garfinkel et al. (2017). Isolate PBC-2 formed concentric colonies that were wooly and whitish to pale gray (Fig. 1C). Conidia that developed from the PDA cultures were $10.5 \pm 1.6 \mathrm{~mm}$ long $\times 6.7 \pm 1.1 \mathrm{~mm}$ wide $(n=50)$. Few sclerotia formed on PDA at room temperature, whereas many melanized structures developed with prolonged incubation, 40 days, at a low temperature of $8^{\circ} \mathrm{C}$. Their shapes were irregular or globular, ranging between 1.5 and $5.3 \mathrm{~mm}$ long $\times 1.6$ and $5.2 \mathrm{~mm}$ wide, with an average of $3.1 \times 3.0 \mathrm{~mm}(n=50)$. This finding suggests that sclerotia could be an overwintering source of the pathogen in the greenhouses.

Because colony morphology, the extent of sporulation, temperature effects, and sclerotia formation are highly variable traits in the Botrytis genus (Garfinkel and Chastagner, 2019), sequences of selected genes were obtained. Initially, sequences were analyzed from the internal transcribed spacer (ITS) region, the large $28 \mathrm{~S}$ subunit rRNA, and the translation elongation factor 1-alpha (tef1) from isolate PBC-

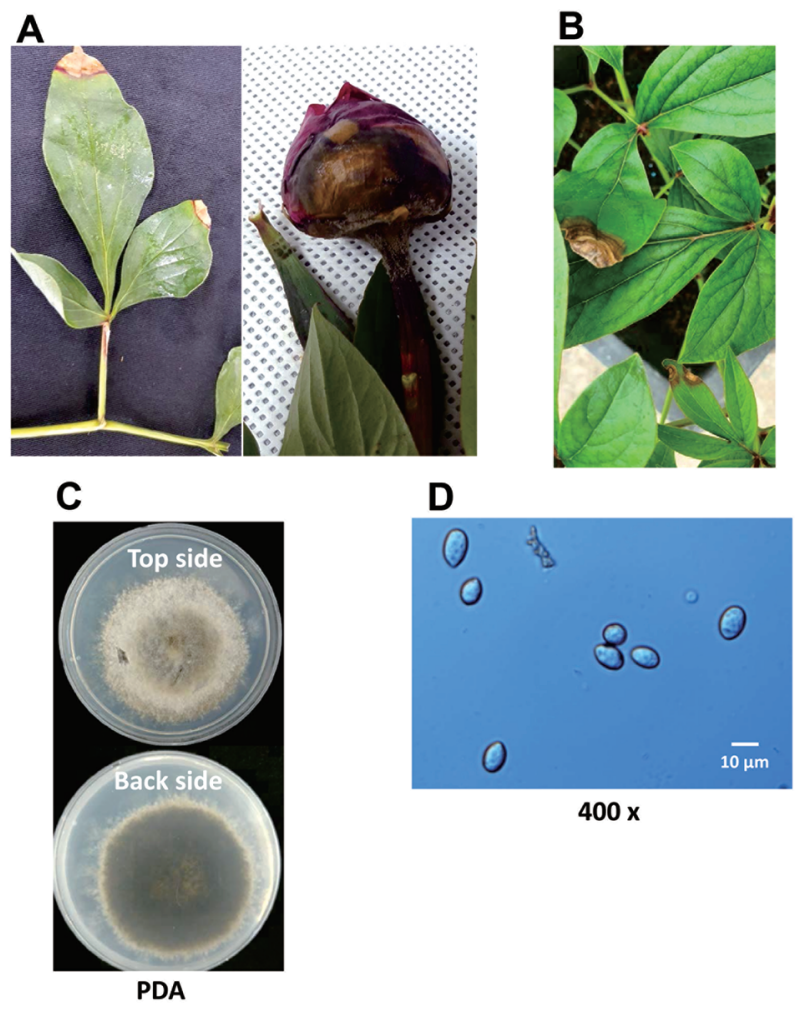

Fig. 1. Gray mold caused by Botrytis cinerea on peonies. (A) Symptoms of gray mold on leaves and flowers of commercial greenhouse-grown peonies. (B) Leaf symptoms of gray mold on the Sarah Bernhardt variety of peony inoculated with the representative strain PBC-2 under laboratory conditions. (C) Two-week-old colony of $B$. cinerea PBC-2 on potato dextrose agar (PDA). (D) Morphological characteristics of the conidia of $B$. cinerea PBC-2 under light microscopy.

2 (Raja et al., 2017; White et al., 1990). BLAST analyses of the resulting 513 bp ITS sequence (GenBank no. MT42213), 1,021 bp large subunit rRNA sequence (MT781367), and 929 bp tef1 sequence (MT87339) of isolate PBC-2 had 100\% identity with type strains of $B$. cinerea isolates. Because of the recent work showing the high extent of diversity within the Botrytis genus, the analysis was extended using sequences for genes encoding glyceraldehyde-3-phosphate dehydrogenase (G3PDH), heat-shock protein 60 (HSP60), and DNAdependent RNA polymerase subunit II (RPB2) (Staats et al. 2005). The GenBank accessions are MT87341, MT87342, and MT87340 for the G3PDH, HSP60, and RPB2 sequences of PBC2 , respectively. Each sequence was $99-100 \%$ identical to $B$. cinerea type strains, MS05 and HA08. Homology to sequences for the same regions from type strains of $B$. paeoniae and $B$. euroamericana were lower (Fig. $2 A-C$ ). Each of these iso- 
lates is associated with gray mold disease on peonies in the United States (Garfinkel and Chastagner, 2019; Garpinkel et al., 2017). Determining whether the outbreak of gray mold in the Korean peonies was caused by a single species requires the sequencing of additional purified cultures.

Studies by Garfinkel and Chastagner (2019) revealed that a variety of symptoms resulted from different isolates of peony origin in the Pacific Northwest of the United States. The symptoms included leaf lesions, as well as bud blast, flower decay, shoot dieback, and basal stem decay, with symptoms dependent on the isolate. The symptoms evident in the commercial greenhouse in the Gangjin County in Korea were the leaf lesions, and abundant gray conidia were formed flowers (Fig. 1A). In this study, only isolates from the diseased leaf spots were grown in the laboratory. Consequently, Koch's postulates were followed to link leaf symptoms with the pathogenicity of isolate PBC-2. Leaves of three healthy 3-month-old plants of $P$. lactiflora 'Sarah Bernhardt' grown in pots were sprayed with a conidial suspension $\left(5 \times 10^{6} \mathrm{co}-\right.$ $\mathrm{nidia} / \mathrm{ml}$ ) of the PBC-2 isolate. The inoculum was prepared from 14-day-old cultures on V8 juice agar grown at $20 \pm 2^{\circ} \mathrm{C}$. Three healthy seedlings were sprayed with sterile water and served as controls. The plants were incubated within a plant growth chamber with a $12 \mathrm{hr}$ light/dark cycle under a halogen light $\left(200 \mu \mathrm{mol} / \mathrm{m}^{2} / \mathrm{sec}\right)$ at a temperature of $20 \pm 1^{\circ} \mathrm{C}$ and relative humidity of $99 \%$. After 7 days, lesions were ob- served on leaves that appeared identical to those observed in the commercial greenhouses. No symptoms developed on the leaves of the control plants. Fungi were re-isolated from the leaf using PDA as the growth medium, and the ITS and tef1 gene sequences within the genome of the isolates were identical to those of the greenhouse-isolate PBC-2. This pathogenicity test was repeated twice with the same results. The fulfillment of Koch's postulates confirmed that $B$. cinerea strains were the causal pathogens of gray blight disease on the peonies.

Gray mold on peonies associated with $B$. cinerea infections has been reported in many other countries, including the United States (Garfinkel and Chastagner, 2019), Serbia (Ivanović et al., 2017), Iran (Mirzaei et al., 2008), and Chile (Muñoz et al., 2016). In spring, the low temperatures (approximately $20^{\circ} \mathrm{C}$ ) and the humidity in the commercial greenhouses afford conditions that promote gray mold development. The finding of the disease caused by $B$. cinerea is a warning regarding the need for integrated management strategies to minimize effects on commercial gains, as well as potential problems for the home grower. As noted by a previous study in the United States (Garfinkel and Chastagner, 2019), Botrytis is a tough pathogen to control because of isolate diversity, its ability to produce both spores and sclerotia, and the evolution of pesticide-resistant variants.
A

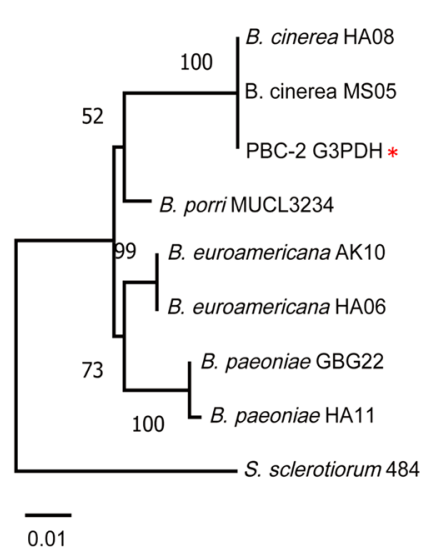

B

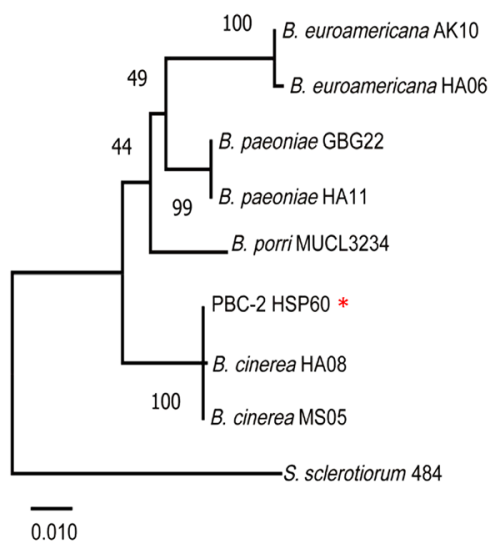

C

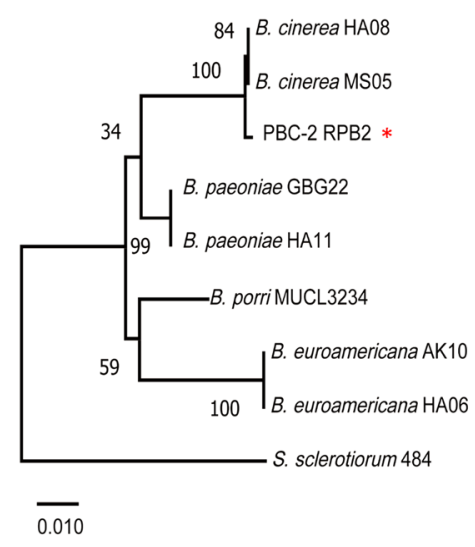

Fig. 2. Maximum likelihood trees for the G3PDH (A), HSP60 (B), and RPB2 (C) gene sequences of the PBC-2 strain and type strains of Botrytis cinerea, B. euroamericana, and B. paeoniae, which have been reported as gray mold pathogens on peonies (Garfinkel et al., 2017). A type strain of B. porri, a causal agent of neck rot in Allium species and Sclerotinia sclerotiorum 484 were used as the outlying sequences. Species names are followed by the isolate/strain. Numerical branch labels represent bootstrap percentages $(n=1,000)$. The branch length is proportional to the number of nucleotide substitutions, as measured by the scale bar. G3PDH, glyceraldehyde-3-phosphate dehydrogenase; HSP60, heat-shock protein 60; RPB2, DNA-dependent RNA polymerase subunit II. 


\section{Conflicts of Interest}

No potential conflict of interest relevant to this article was reported.

\section{Acknowledgments}

This work was supported by the Cooperative Research Program for Agriculture Science \& Technology Development (project no. PJ012710022020), Rural Development Administration, Republic of Korea.

\section{References}

Choi, Y.-W., Hyde, K. D. and Ho, W. W. H. 1999. Single spore isolation of fungi. Fungal Divers. 3: 29-38.

Ellis, M. V. and Waller, J. M. 1974. CMI Descriptions of Pathogenic Fungi and Bacteria. No. 431. Commonwealth Mycological Institute, Kew, Surrey, UK. 2 pp.

Garfinkel, A. R. and Chastagner, G. A. 2018. Diseases of peonies. In: Handbook of Florists' Crops Diseases, eds. by R. J. McGovern and W. H. Elmer, pp. 663-692. Springer International Publishing, Cham, Switzerland.

Garfinkel, A. R. and Chastagner, G. A. 2019. Survey reveals a broad range of fungal pathogens and an oomycete on peonies in the United States. Plant Health Prog. 20: 250-254.

Garfinkel, A. R., Lorenzini, M., Zapparoli, G. and Chastagner, G. A. 2017. Botrytis euroamericana, a new species from peony and grape in North America and Europe. Mycologia 109: 495-507.

Ivanović, Ž., Blagojević, J., Popović, T. and Ignjatov, M. 2017. First report of botrytis blight caused by Botrytis cinerea on Paeonia lactiflora in Serbia. Plant Dis. 101: 1677.

Mirzaei, S., Mohammadi Goltapeh, E., Shams-Bakhsh, M. and Safaie, N. 2008. Identification of Botrytis spp. on plants grown in Iran. J. Phytopathol. 156: 21-28.

Muñoz, G., Campos, F., Salgado, D., Galdames, R., Gilchrist, L., Chahin, G. et al. 2016. Molecular identification of Botrytis cinerea, Botrytis paeoniae and Botrytis pseudocinerea associated with gray mould disease in peonies (Paeonia lactiflora Pall.) in Southern Chile. Rev. Iberoam. Micol. 33: 43-47.

Raja, H. A., Miller, A. N., Pearce, C. J. and Oberlies, N. H. 2017. Fungal identification using molecular tools: a primer for the natural products research community. J. Nat. Prod. 80: 756-770.

Staats, M., van Baarlen, P. and van Kan, J. A. L. 2005. Molecular phylogeny of the plant pathogenic genus Botrytis and the evolution of host specificity. Mol. Biol. Evol. 22: 333-346.

White, T. J., Bruns, T., Lee, S. and Taylor, J. 1990. Amplification and direct sequencing of fungal ribosomal RNA genes for phylogenetics. In: PCR Protocols: A Guide to Methods and Applications, eds. by M. A. Innis, D. H. Gelfand, J. J. Sninsk and T. J. White, pp. 315322. Academic Press, San Diego, CA, USA. 